\section{Antimicrobial resistance of} Staphylococcus aureus, fecal streptococci, Enterobacteriaceae and Pseudomonas aeruginosa isolated from the coastal water of the Gaza strip-Palestine

Elmanama Abdelraouf A. ${ }^{1}$, Hartemann Philippe ${ }^{2}$, Elnabris Kamal J. ${ }^{3}$, Ayesh Adnan ${ }^{4}$, Afifi Samir ${ }^{5}$, Elfara Fatma ${ }^{5}$, Aljubb Alaa R. ${ }^{5}$

1 Medical laboratory Sciences Department, Islamic university-Gaza, P.O Box, 108, Gaza, Palestine

2 Université Nancy Lorraine, Nancy, France

3 Biology Department, Islamic university-Gaza, P.O Box, 108, Gaza, Palestine

4 Geology Department, Al Azhar University- Gaza, P.O. Box 1277, Palestine

5 Earth and environmental Science department, Islamic university-Gaza, P.O Box, 108, Gaza, Palestine

Methods: Seawater samples were collected at 16 location distributed along the coast of the Gaza strip. Sampling was accomplished during 12 months, from March 2014 to June 2015. The microbial composition including Enterobacteriaceae, Staphylococcus aureus, fecal streptococci and Pseudomonas aeruginosa was recorded and tested for their resistance to specific antimicrobial agents according to CLSI using the disc diffusion method.

Results: A total of 816 isolates of Enterobacteriaceae (377), S. aureus (29), fecal enterococci (FS) (369), and $P$. aeruginosa (29) were recovered and identified. Enterobacteriaceae, $P$. aeruginosa, FS and $S$. aureus isolates exhibited the highest rates of resistance against $\beta$-lactam drugs. The isolates also showed resistance to at least one antimicrobial in the range between 99.7 to $78 \%$. Multiple resistance occurred in almost $85 \%$ of all isolates; $99.2 \%$ of Enterobacteriaceae, $96.6 \%$ of $P$. aeruginosa, $72.1 \%$ of FS and $61 \%$ of S.aureus. The incidence of multiple resistance of isolates from all sampling locations ranged from 69.2 to $94.1 \%$. Antibiotic resistance indices were found to be highest in $P$. aeruginosa (0.57), followed by E. coli $(0.53)$, FS (0.49), Enterobacter (0.41), S. marcescens (0.40), Klebsiella (0.39) and
Corresponding author:

Dr. Abdelraouf A. Elmanama

” elmanama@iugaza.edu.ps 
finally Proteus (0.28). Most of the isolates showed multiple antibiotic resistance (MAR) index value higher than 0.2.

Conclusions: This study demonstrated that the seawater of the Gaza strip is highly contaminated with antibiotic resistant bacteria which can be transmitted to humans through recreational and other activities. Therefore, there is a need to apply appropriate and rationale use of antibiotic to minimize the occurrence of multiple antibiotic resistant bacteria in the marine environment. Proper treatment of sewage before it is discharged to the sea is highly recommended.

Keywords: Multiple antimicrobial resistance, Gaza strip, seawater, fecal enterococci, $P$. aeruginosa, Enterobacteriaceae, S. aureus.

\section{Introduction}

Antimicrobial drugs are used worldwide, not only to treat infectious diseases, but also to act as prophylactic agents to prevent infections, to promote growth in agriculture and aquaculture, and to preserve food [1]. Human intensive and uncontrolled use of antibiotics in medicine, veterinary and agricultural practices have probably led to emergence and spread of antibiotic resistant bacteria in the environments [2].

Generally, bacteria may develop antibiotic resistance by spontaneous chromosomal mutations in the bacterial genome or by acquiring resistance genes through horizontal gene transfer between different bacterial species through conjugation, transformation or transduction [3].

In the Gaza strip, there is growing evidence that the misuse and overuse of antibiotics are the major contributors to the development and spread of antibiotic resistance bacteria in our region. In fact, no regulation exists regarding the use and dispense of antibiotics in the Gaza Strip. Although the problem of drug resistance is not new, the scale of the problem in this region has received little attention. Previous studies of the antibiotic resistance problem have mainly focused on nosocomial infections caused by multidrug resistant pathogens [4-9]. There was only one study, which has investigated the contribution of hospital effluents in spreading of antibiotic resistance in the Gaza's environment [10].

Currently, the pollution of coastal areas represents one of the most difficult challenges because it causes economic damages as well as affects general health of people. Besides that, such pollution may also accelerate the emergence of antibiotic resistance bacteria in marine environment which posing serious threats to humans health and aquatic ecosystems by the increasing the load of antimicrobial resistant bacteria in nature [11].

The effluents of wastewater treatment plants, Wadi Gaza and some sewage outlets from seaside residences, marine fish farms effluents are the main sources of marine pollution with antimicrobial resistance in Gaza strip.

Apart from the adverse effects, several studies suggested that antibiotic resistant bacteria could provide an important indicator of marine water quality and its potential health risk [12-15]. Accordingly, calls have been made to consider testing for antibiotic resistance when establishing bacteriologi- 
cal water quality criteria [16]. Recently, the concept of antibiotic resistance was used as a cost effective technique for tracking the source bacterial pollution in the environment [2].

There are no local published studies or reports regarding the occurrence of antimicrobial resistant in marine environments. To our best knowledge, this is the first study aimed to detect the presence of antimicrobial resistance in pathogenic bacteria of seawater samples collected from marine environment in the Gaza strip. The objective of the present study was to document the occurrence and distribution of antimicrobial resistant of clinically important bacteria in the seawater of Gaza strip; and to assess the microbiological safety of coastal water of the Gaza strip.

\section{Materials and Methods}

Sampling locations. Seawater samples were collected at 16 locations distributed along the coast of the Gaza strip (Figure 1). Sampling site selection was based on a number of criteria including pre-existing studies and reports, site access and its suitability for sampling and most importantly the different anthropogenic activities to which they are thought to be exposed.

All sampling sites were identified by geographic coordinates as determined by a hand-held Global Positioning System . Samples were collected twice a month, over the period from March 2014 to June 2015. A total of 24 samples from each location were collected for analysis. All tests were carried out at the Environmental and Rural Research Center at the Islamic University of Gaza and the Water Institute of Al-Azhar University Gaza-Palestine.

\section{Sample Collection and Processing}

Sampling was conducted according to the World Health Organization Manual for Recreational Water and Beach Quality Monitoring and Assessment WHO (1995) [17]. Seawater samples were collected

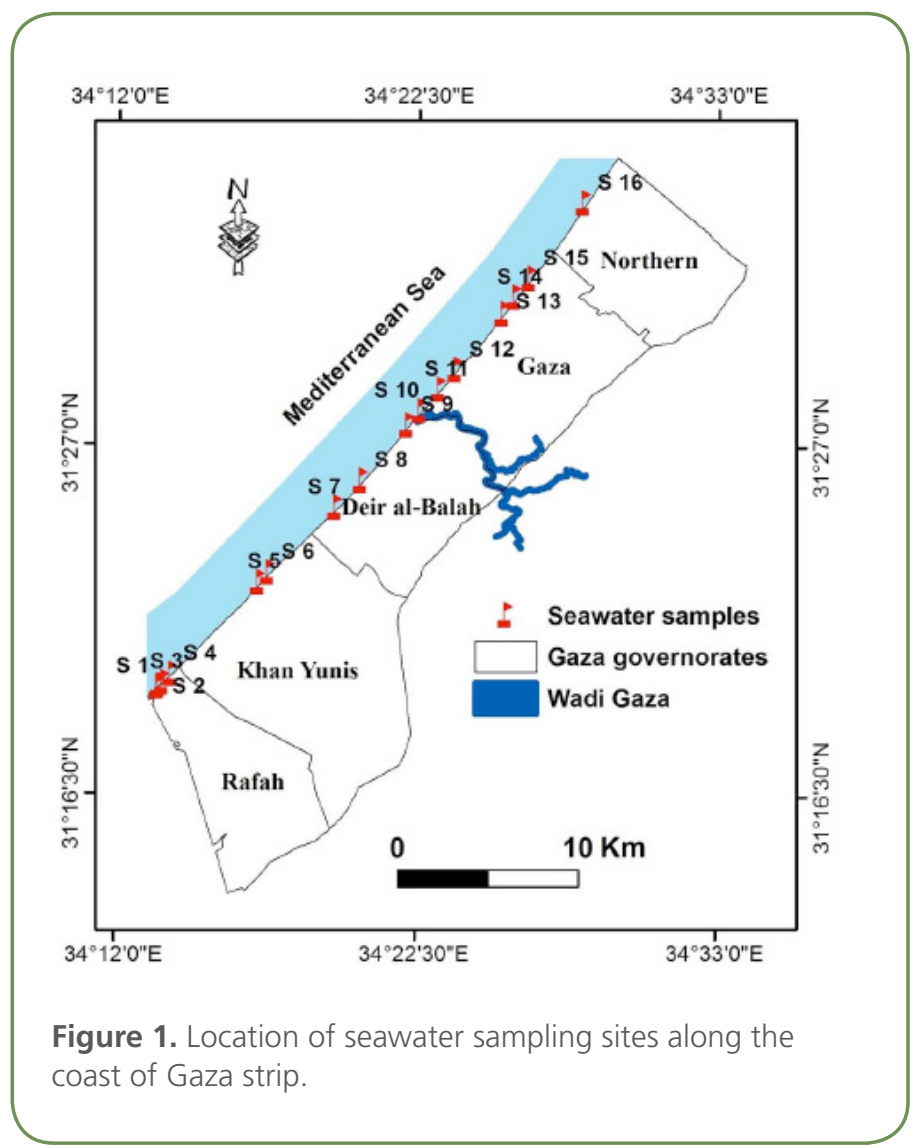

in $2 \mathrm{~L}$ sterile containers. The bottles were rinsed $2-3$ times with seawater from the same site before collection, the lid of the bottle was removed, turned upside down, gently lowered approximately 20-30 $\mathrm{cm}$ below the water surface and then turned so that mouth was pointing upward. When the bottle was approximately 2/3 filled, it was lifted above the surface and immediately the lid was placed back on the bottle. All collected samples were kept immediately at $4^{\circ} \mathrm{C}$ in an icebox and transported to the laboratory for analysis within two hours of collection.

Isolation of Bacteria. Under strict aseptic conditions, appropriate volumes of seawater samples were filtered through $0.45 \mu \mathrm{m}$ membrane filters. The filters were then placed on M-FC, m-FS, cetrimide agar and Baird-Parker media for growing of fecal coliform (FC), fecal enterococci , P. eruginosa and $S$. aureus respectively. The plates were incubated at $44-45^{\circ} \mathrm{C}$ for $18-24 \mathrm{~h}$ for fecal coliform, at 
$41 \pm 0.5^{\circ} \mathrm{C}$ for $48 \mathrm{~h}$ for enterococci, at $35^{\circ} \mathrm{C}$ for 24 $\mathrm{h}$ for $P$. aeruginosa and at $35 \pm 0.5^{\circ} \mathrm{C}$ for $48 \pm 4 \mathrm{~h}$ for $S$. aureus. One Blood agar and one MacConkey plates were streaked and incubated at $35 \pm 0.5^{\circ} \mathrm{C}$ for 24 hours for isolation of potential pathogens.

\section{Bacterial Identification}

Preliminary identification of colonies was determined based on morphological characteristics and pigment production on selective media. Various shades of blue colonies on m-FC medium indicated fecal coliform, red colony with a metallic sheen on FS agar indicated streptococci, yellow-green color on Cetrimide agar indicated Pseudomonas, smooth and entire colonies with grey to black coloration on Baird-Parker agar indicated Staphylococcus. For the purpose of confirmation, singly growing colonies were picked and purified by re-streaking on fresh media. Pure colonies were then subjected to biochemical tests such as Oxidase, Catalase and API kit (BioMérieux- France) to confirm the identity of the isolated bacteria prior to subsequent antimicrobial susceptibility testing.

\section{Antimicrobial Susceptibility testing}

Susceptibility of all isolates were investigated against commercially available antibiotic discs ( $\mathrm{Hi}$ media) using the standard disk diffusion assay and antimicrobial compounds as guided by Clinical and Laboratory Standards Institute (CLSI). Based on inhibition zone, the isolates were categorized as resistant, intermediate or susceptible to the tested antimicrobials[ 18].

\section{Multiple Antimicrobial Resistance Index (MARI)}

In the current study, MAR index for the isolates was generated for antibiotics as well as for the sites. The MAR index for each isolate was calculated by following the procedure described by Krumperman, P. (1983) using the following formula; number of antimicrobial agents to which the isolate was resistant/ total number of antimicrobials against which isolate was tested[19]. On the other hand, the MAR index for each sample site was calculated as the number of antimicrobials to which all isolates were resistant/ (number of antimicrobials tested $\times$ number of isolates tested per site) [20].

\section{Data analysis}

Resistance to antimicrobial agents was expressed as percentage. Multiple Antibiotic Resistance index(MARI)for the different isolates and locations was calculated. One way analysis of variance (ANOVA) and multiple comparison testing was performed to determine significant differences among the MAR indices from different sites. Before analysis, all in dices were arcsine transformed to improve normality. Correlations between the geometric means of fecal indicators (fecal coliform and fecal enterococci) and percentage of isolate resistant with respect to different stations were calculated using the Pearson's correlation coefficient. Probabilities $<0.05$ were considered significant. Statistical analyses in this study were carried out with SPSS(Statistic Package for the Social Science).

\section{Results}

Geometric means for the densities of the fecal indicator bacteria, fecal coliform (FC) and fecal enterococci in seawater samples collected from the 16 sites are presented in Figure 2. The populations of FS were higher than that of FC at all locations, with geometric means ranged from 248.9-8481.5 for FS and $143.6-3534.3 \mathrm{cfu} / 100 \mathrm{ml}$ for FC. The maximum populations of both FC and FS in seawater samples were observed at S15 with geometric mean values of $3.53 \times 10^{3}$ and $8.48 \times 10^{3} \mathrm{cfu} / 100 \mathrm{ml}$ respectively, followed by $\mathrm{S} 12\left(3.48 \times 10^{3}\right.$ and $\left.6.60 \times 10^{3}\right)$, S10 $\left(2.75 \times 10^{3}\right.$ and $\left.3.93 \times 10^{3}\right)$ and S14 $\left(1.74 \times 10^{3}\right.$ and $\left.3.54 \times 10^{3}\right)$. 


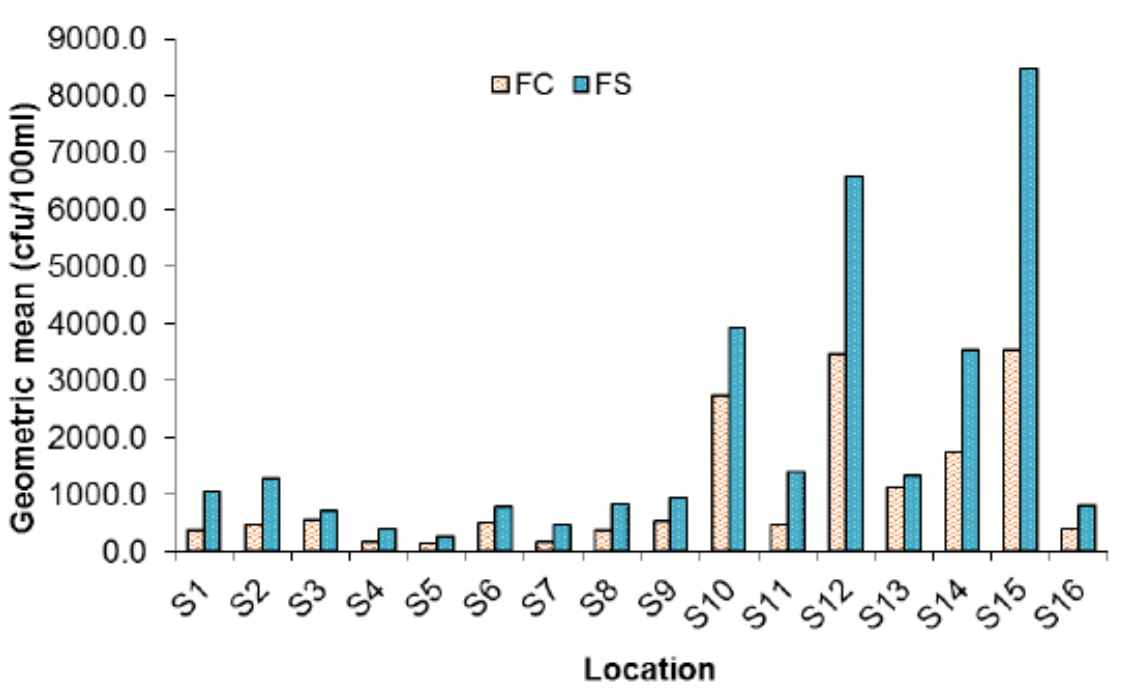

Figure 1. Geometric mean of fecal coliform (FC) and fecal enterococci (FS) in seawater samples at 16 locations.

\section{Bacterial isolates}

A total of 816 bacterial isolates were identified to at least the genus level, and examined for antibiotic resistance test by using a selected list of antimicrobial agents for each bacterial group. These isolates (410 gram positive and 406 gram negative) belonging to four groups, including 377 Enterobacteriaceae, 369 fecal enterococci , 29 S. aureus and 29 isolates were belong to Pseudomonas. Enteric bacterial isolates belonged to five genera, with $E$. coli being the most frequent species ( 272 isolate), followed by 83 isolate of Klebsiella spp., 11 of Enterobacter spp., 8 of Serratia marcescens and 3 of Proteus vulgaris.

\section{Resistance profile of bacterial isolates}

Table 1 shows the resistance percentage of isolates to different antibiotics. Bacterial groups displayed varying resistance to the tested antimicrobial agents, with Gram-negative bacteria (Enterobacteriaceae and $P$. eruginosa) showing higher resistance than Gram-positive bacteria (FE and S. aureus). Enterobacteriaceae as a group exhibited high rates of resistance against ampicillin and amoxicillin. Amikacin followed by ciprofloxacin and gentamicin were the most effective with resistance rates of 2.1, 26.8 and $28.4 \%$ respectively. An overall notable resistance against Imipenem was recorded (57.6\%) with $100 \%$ resistance of the 3 Proteus isolates. P. aeruginosa isolates showed phenomenal resistance against the three tested carbapenems; meropnem (86.2\%), imipnem (96.6\%) and ertapnem 93.1\%. amikacin showed the highest activity (only $2.1 \%$ resistance).

S. aureus showed high percentage of resistance to $\beta$-lactam antibiotics, which include the penicillin G (65.9\%) and oxacillin (61\%) which are used to detect methicillin resistance. Vancomycin resistance was strikingly high (48.8\%). Ciprofloxacin and gentamicin showed the greatest efficacy with only $2.4 \%$ resistance, followed by doxycycline and chloramphenicol (4.9\% resistance). FS resistance was $16.8 \%$ and $39.6 \%$ to linezolid and vancomycin respectively. Highest resistance was detected against penicillin G (75.1\%) and ampicillin (76.7\%). 
Table 1. Antibiotic resistance profile of pathogenic bacteria isolated from the seawater samples of all studiedsites (\%).

\begin{tabular}{|c|c|c|c|c|c|c|c|c|c|}
\hline \multirow[b]{3}{*}{ Antimicrobial agent } & \multicolumn{9}{|c|}{$\%$ resistant } \\
\hline & \multicolumn{6}{|c|}{ Enterobcteriaceae } & \multirow[b]{2}{*}{$\begin{array}{l}\widehat{\bar{J}} \\
\overline{0} \\
\overline{0} \\
\text { v }\end{array}$} & \multirow[b]{2}{*}{ 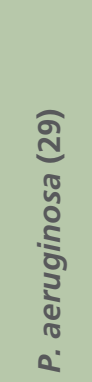 } & \multirow[b]{2}{*}{ 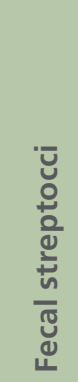 } \\
\hline & 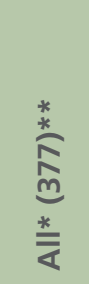 & 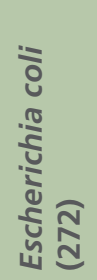 & 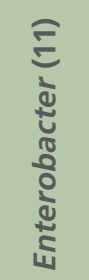 & 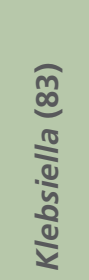 & 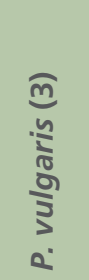 & 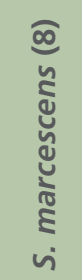 & & & \\
\hline Amikacin & 2.1 & 2.2 & 0.0 & 2.0 & 0.0 & 0.0 & NT & 3.4 & NT \\
\hline Amoxicillin & 97.1 & 97.8 & 100 & 95.2 & 66.7 & 100 & NT & NT & NT \\
\hline Ampicillin & 98.7 & 98.9 & 100 & 98.8 & 66.7 & 100 & NT & NT & 76.7 \\
\hline Azithromycin & NT & NT & NT & NT & NT & NT & 14.6 & NT & NT \\
\hline Aztreonam & 30.2 & 36 & 18.2 & 15.7 & 0.0 & 12.5 & NT & 31 & NT \\
\hline Ceftrazidime & 40.1 & 45.6 & 18.2 & 25.3 & 33.3 & 37.5 & NT & NT & NT \\
\hline Ceftriaxone & NT & NT & NT & NT & NT & NT & NT & 34.5 & NT \\
\hline Cefuroxime & 71.9 & 77.6 & 54.5 & 55.4 & 66.7 & 75.0 & NT & NT & NT \\
\hline Chloramphenicol & 36.1 & 42.6 & 18.2 & 19.3 & 00.0 & 25.0 & 4.9 & NT & NT \\
\hline Ciprofloxacin & 26.8 & 31.3 & 18.2 & 15.7 & 00.0 & 12.5 & 2.4 & 37.9 & NT \\
\hline Clindamycin & NT & NT & NT & NT & NT & NT & 36.6 & NT & NT \\
\hline Doxycycline & NT & NT & NT & NT & NT & NT & 4.9 & NT & NT \\
\hline Ertapenem & NT & NT & NT & NT & NT & NT & NT & 93.1 & NT \\
\hline Gentamicin & 28.4 & 29 & 27.3 & 30.1 & 00.0 & 00.0 & 2.4 & 34.5 & 42.3 \\
\hline Imipenem & 57.6 & 60.7 & 63.6 & 45.8 & 100 & 50 & NT & 96.6 & NT \\
\hline Linezolid & NT & NT & NT & NT & NT & NT & NT & NT & 16.8 \\
\hline Meropenem & NT & NT & NT & NT & NT & NT & NT & 86.2 & NT \\
\hline Ofloxacin & NT & NT & NT & NT & NT & NT & NT & NT & 40.1 \\
\hline Oxacillin & NT & NT & NT & NT & NT & NT & 61 & NT & NT \\
\hline Penicillin G & NT & NT & NT & NT & NT & NT & 65.9 & NT & 75.1 \\
\hline Piperacillin & 50.7 & 57.4 & 45.5 & 33.7 & 00.0 & 25 & NT & 51.7 & NT \\
\hline Rifampin & NT & NT & NT & NT & NT & NT & 12.2 & NT & NT \\
\hline Tetracycline & 36.9 & 44.1 & 18.2 & 18.1 & 00.0 & 25.0 & NT & NT & NT \\
\hline Trimethoprim/Sulfonamides & 64.7 & 67.6 & 54.5 & 57.8 & 33.3 & 62.5 & 17.1 & NT & NT \\
\hline Vancomycin & NT & NT & NT & NT & NT & NT & 48.8 & NT & 39.6 \\
\hline
\end{tabular}

* All Enterobacteriaceae isolates tested.

**Values in parentheses indicates the number of isolates examined

NT: Not tested 


\section{The incidence of multidrug resistance}

The incidence of multiple resistance, that is, the simultaneous resistance to more than one antimicrobial agent for all isolates from the different sampling locations are listed in Table 2. The incidence of multiple resistance occurred in $85 \%$ of all isolates and was $99.2 \%$ for Enterobacteriaceae $(99.6 \%$ for E. coli, $97.6 \%$ for Klebsiella spp., and $100 \%$ for
Enterobacter spp., P. vulgaris and S. marcescens), $96.6 \%$ for $P$. aeruginosa, $72.1 \%$ for $\mathrm{FS}$, and $61 \%$ for $S$. aureus. Similarly, the incidence of multiple resistance for all isolates from the 16 sampling locations were ranged from 69.2 to $94.1 \%$, with the highest incidence occurring at S15 and S16 while lowest incidence occurred at S4 and S5.

Table 2. The incidence of multiple resistance of the isolated pathogens from the different sampling sites.

\begin{tabular}{|c|c|c|c|c|c|c|c|c|c|c|}
\hline \multirow[b]{2}{*}{ Sampling sites } & \multicolumn{6}{|c|}{ Enterobacteriaceae } & \multirow[b]{2}{*}{ 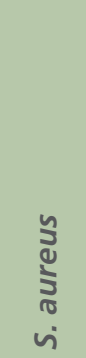 } & \multirow[b]{2}{*}{ 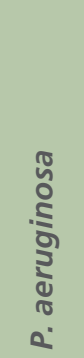 } & \multirow[b]{2}{*}{ 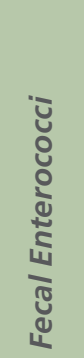 } & \multirow[b]{2}{*}{$\begin{array}{l}\bar{J} \\
\stackrel{0}{0}\end{array}$} \\
\hline & $\stackrel{*}{\frac{*}{\alpha}}$ & $\begin{array}{l}\text { ¿े } \\
\text { ن }\end{array}$ & $\begin{array}{l}\frac{0}{\frac{\omega}{n}} \\
\frac{0}{\varrho}\end{array}$ & 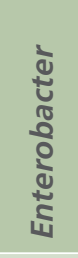 & 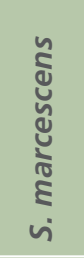 & $\begin{array}{l}\frac{n}{2} \\
\frac{\pi}{2} \\
\frac{0}{3} \\
0 \\
0\end{array}$ & & & & \\
\hline S1 & 95.5 & 93.8 & 100 & $\mathrm{~N}$ & $\mathrm{~N}$ & 100 & 100 & 0.0 & 61.1 & 80.0 \\
\hline S2 & 95.7 & 100 & 83.3 & $\mathrm{~N}$ & $\mathrm{~N}$ & $\mathrm{~N}$ & 50.0 & $\mathrm{~N}$ & 70.8 & 80.4 \\
\hline S3 & 100 & 100 & 100 & $\mathrm{~N}$ & $\mathrm{~N}$ & $\mathrm{~N}$ & 33.3 & 100 & 68.2 & 80.0 \\
\hline S4 & 100 & 100 & 100 & $\mathrm{~N}$ & $\mathrm{~N}$ & $\mathrm{~N}$ & 100 & $\mathrm{~N}$ & 54.5 & 73.0 \\
\hline S5 & 100 & 100 & 100 & $\mathrm{~N}$ & $\mathrm{~N}$ & $\mathrm{~N}$ & 0.0 & $\mathrm{~N}$ & 52.4 & 69.2 \\
\hline S6 & 100 & 100 & 100 & 100 & 100 & $\mathrm{~N}$ & 100 & 100 & 73.1 & 87.0 \\
\hline S7 & 100 & 100 & 100 & $\mathrm{~N}$ & $\mathrm{~N}$ & $\mathrm{~N}$ & $\mathrm{~N}$ & $\mathrm{~N}$ & 66.7 & 78.1 \\
\hline S8 & 100 & 100 & 100 & $\mathrm{~N}$ & $\mathrm{~N}$ & $\mathrm{~N}$ & 50.0 & $\mathrm{~N}$ & 66.7 & 81.6 \\
\hline S9 & 100 & 100 & 100 & $\mathrm{~N}$ & 100 & $\mathrm{~N}$ & 00.0 & 100 & 87.0 & 92.0 \\
\hline $\mathrm{S} 10$ & 96.9 & 100 & 90.9 & 100 & $\mathrm{~N}$ & $\mathrm{~N}$ & 66.7 & 100 & 83.3 & 90.5 \\
\hline S11 & 100 & 100 & 100 & $\mathrm{~N}$ & 100 & $\mathrm{~N}$ & 25.0 & 100 & 66.7 & 81.7 \\
\hline $\mathrm{S} 12$ & 100 & 100 & 100 & $\mathrm{~N}$ & 100 & $\mathrm{~N}$ & 100 & 100 & 72.0 & 89.7 \\
\hline $\mathrm{S} 13$ & 100 & 100 & 100 & 100 & 100 & $\mathrm{~N}$ & 100 & 100 & 71.4 & 85.5 \\
\hline $\mathrm{S} 14$ & 100 & 100 & 100 & $\mathrm{~N}$ & 100 & 100 & 50.0 & 100 & 81.0 & 89.3 \\
\hline S15 & 100 & 100 & 100 & 100 & $\mathrm{~N}$ & $\mathrm{~N}$ & 83.3 & 100 & 88.0 & 94.1 \\
\hline $\mathrm{S} 16$ & 100 & 100 & 100 & 100 & 100 & $\mathrm{~N}$ & 50.0 & $\mathrm{~N}$ & 85.7 & 90.9 \\
\hline Total & 99.2 & 99.6 & 97.6 & 100 & 100 & 100 & 61.0 & 96.6 & 72.1 & 84.9 \\
\hline
\end{tabular}

$\mathrm{N}$ : Not detected * All Enterobacteriaceae isolates tested. 


\section{Multidrug resistance of bacterial isolates}

Most of the isolates showed resistance to multiple antibiotics. A prominent proportion of Enterobacteriaceae (15.4\%) and S. aureus $(19.5 \%)$ isolates exhibited simultaneous resistance against four antimicrobials, whereas FS resistant $(21.4 \%)$ to one antimicrobial agent followed by two (17.1\%), four and five (15.7\%) agents (Table 3).

The highest resistance $(24.1 \%)$ among $P$. aeruginosa isolates was observed to three antimicrobial agents. Only small fraction $(0.3,22,3.4$ and $6.5 \%)$ of tested Enterobacteriaceae, S. aureus, P.aeruginosa and FS demonstrated susceptibility to the all agents used in the study (13,11,9 and 6, respectively).

On the other hand, 99.7, 78, 96.6 and 78.6\% of Enterobacteriaceae, $S$. aureus, P.aeruginosa and FS isolates respectively showed resistance to at least one antimicrobial. Among Enterobacteriaceae; Enterobacter spp., Klebsiella spp.and E. coli showed higher multi-resistance levels than $P$. vulgaris and S. marcescens, as they (the former) showed resistance to as many as 11, 12 and 13 antibiotics (out of the 13 tested antimicrobials), while no bacterial resistant to more than 5-8 were observed among the later two species, respectively. Moreover, the data indicates that more than a half (52.6-93.5\%) of the tested bacterial strains were resistant to 1-6 antibiotics, whereas minimal percentage $(<50 \%)$ of these organisms showed resistance to the remaining antibiotics (if any). Except for four isolates (1.5\%) of $E$. coli and 32 (8.7\%) isolates of FS, no bacteria inhabiting the studied sites were resistant to all tested antibiotics.

Table 3. Percentage of bacterial resistance to antibiotics

\begin{tabular}{|c|c|c|c|c|c|c|c|c|c|}
\hline \multirow[b]{3}{*}{$\begin{array}{l}\text { No. of antibiotics } \\
\text { to which isolate is } \\
\text { resistant }\end{array}$} & \multicolumn{9}{|c|}{$\%$ of isolates } \\
\hline & \multicolumn{6}{|c|}{ Enterobacteriaceae } & \multirow[b]{2}{*}{$\begin{array}{l}\underset{ \pm}{ \pm} \\
\frac{n}{0} \\
\frac{0}{5} \\
\text { v } \\
\text { vi }\end{array}$} & \multirow[b]{2}{*}{ 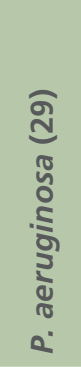 } & \multirow{2}{*}{ 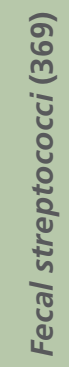 } \\
\hline & 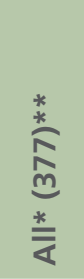 & 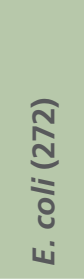 & 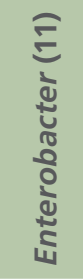 & $\begin{array}{l}\frac{\pi}{m} \\
\infty \\
\frac{0}{a} \\
\frac{o}{n} \\
\frac{0}{0}\end{array}$ & $\begin{array}{l}\frac{\pi}{m} \\
\frac{n}{5} \\
\frac{0}{3} \\
\frac{3}{3} \\
0\end{array}$ & 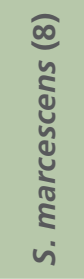 & & & \\
\hline 0 & 0.3 & 0.0 & 0.0 & 1.2 & 0.0 & 0.0 & 22.0 & 3.4 & 6.5 \\
\hline 1 & 0.5 & 0.4 & 0.0 & 1.2 & 0.0 & 0.0 & 17.1 & 0.0 & 21.4 \\
\hline 2 & 7.4 & 5.9 & 27.3 & 9.6 & 33.3 & 0.0 & 7.3 & 6.9 & 17.1 \\
\hline 3 & 12.7 & 11.4 & 0.0 & 16.9 & 0.0 & 37.5 & 14.6 & 24.1 & 14.9 \\
\hline 4 & 15.4 & 13.2 & 27.3 & 20.5 & 33.3 & 12.5 & 19.5 & 17.2 & 15.7 \\
\hline 5 & 10.6 & 9.6 & 9.1 & 14.5 & 33.3 & 0.0 & 12.2 & 17.2 & 15.7 \\
\hline 6 & 10.6 & 12.1 & 9.1 & 6.0 & 0.0 & 12.5 & 2.4 & 6.9 & 8.7 \\
\hline 7 & 6.6 & 5.5 & 0.0 & 10.8 & 0.0 & 12.5 & 0.0 & 6.9 & \\
\hline 8 & 7.2 & 6.6 & 0.0 & 8.4 & 0.0 & 25.0 & 2.4 & 17.2 & \\
\hline 9 & 5.8 & 6.6 & 9.1 & 3.6 & 0.0 & 0.0 & 2.4 & 0.0 & \\
\hline 10 & 7.7 & 8.8 & 9.1 & 4.8 & 0.0 & 0.0 & 0.0 & & \\
\hline 11 & 6.6 & 8.5 & 9.1 & 1.2 & 0.0 & 0.0 & 0.0 & & \\
\hline 12 & 7.4 & 9.9 & 0.0 & 1.2 & 0.0 & 0.0 & & & \\
\hline 13 & 1.1 & 1.5 & 0.0 & 0.0 & 0.0 & 0.0 & & & \\
\hline
\end{tabular}

* All Enterobacteriaceae isolates tested.

**Values in parentheses indicates the number of isolates examined. 


\section{Multiple Antibiotic Resistance Index (MARI)}

The MAR index values for isolated strains from the different locations and the percentage of MAR index value $>0.2$ are given in Table 4 . The overall MARI value for all isolates $(n=816)$ from all locations was found to be 0.48 and $81 \%$ of these isolates have MARI values higher than 0.2. The MARI value for isolates were ranged from an average of 0.25 (S. aureus) to 0.57 ( $P$. aeruginosa). The MAR index values for other strains were as follows; 0.53 for $E$. coli, 0.49 for FS , 0.41 for FS, 0.40 for S. marcescens, 0.39 for Klebsiella and 0.28 for Proteus. Among theisolates, $92 \%$ of Enterobacteriaceae, $72 \%$ of $\mathrm{FS}$, $54 \%$ of $S$. aureus and $97 \%$ of $P$. aeruginosa had a high MAR index value $(>0.2)$.

For all the sites, the percentage of MARI $>0.2$ ranged from $61 \%$ (S5) to $91 \%$ (S15). The highest antimicrobial resistance was detected among the bacteria isolated from S15 (MARI 0.61), followed by S10 (MARI 0.57), S12 (MARI 0.55), S11 (MARI 0.52), S2, S9, S14 (MARI 0.49), S13 (MARI 0.47), S8 (MARI 0.46), S16 (MARI 0.45), S6 (MARI 0.44), S3 (MARI 0.43 ), S1, S7 (MARI 0.41) and finally S4 and S5 with MARI value of 0.33 .

Despite the observed differences among the

Table 4. Multiple antibiotic resistance index of the isolated strains from different stations (\%) and the percentage of MAR index value $>0.2$

\begin{tabular}{|c|c|c|c|c|c|c|c|c|c|c|c|}
\hline \multirow[b]{2}{*}{ Sampling sites } & \multicolumn{6}{|c|}{ Enterobacteriaceae } & \multirow{2}{*}{ 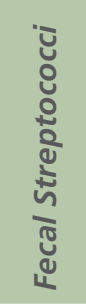 } & \multirow[b]{2}{*}{ 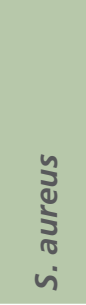 } & \multirow[b]{2}{*}{ 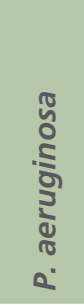 } & \multirow[b]{2}{*}{ Total } & \multirow[b]{2}{*}{$\begin{array}{l}\text { Isolates with } \\
\text { MARI value } \\
>0.2(\%)\end{array}$} \\
\hline & $\stackrel{*}{\frac{*}{\alpha}}$ & $\begin{array}{l}\text { ¿े } \\
\text { نे }\end{array}$ & $\frac{\frac{\pi}{2}}{\frac{0}{4}}$ & 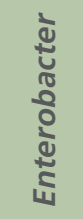 & 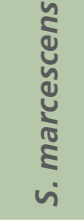 & $\begin{array}{l}\frac{0}{2} \\
n \\
\frac{n}{2} \\
0 \\
0 \\
0 \\
0\end{array}$ & & & & & \\
\hline S1 & 0.41 & 0.46 & 0.28 & $\mathrm{~N}$ & $\mathrm{~N}$ & 0.15 & 0.46 & 0.03 & 0.0 & 0.41 & 71 \\
\hline S2 & 0.52 & 0.57 & 0.41 & $\mathrm{~N}$ & $\mathrm{~N}$ & $\mathrm{~N}$ & 0.51 & 0.20 & $\mathrm{~N}$ & 0.49 & 78 \\
\hline S3 & 0.51 & 0.52 & 0.42 & $\mathrm{~N}$ & $\mathrm{~N}$ & $\mathrm{~N}$ & 0.40 & 0.12 & 0.56 & 0.43 & 80 \\
\hline S4 & 0.31 & 0.29 & 0.38 & $\mathrm{~N}$ & $\mathrm{~N}$ & $\mathrm{~N}$ & 0.34 & 0.27 & $\mathrm{~N}$ & 0.33 & 68 \\
\hline S5 & 0.36 & 0.35 & 0.38 & $\mathrm{~N}$ & $\mathrm{~N}$ & $\mathrm{~N}$ & 0.33 & 0.05 & $\mathrm{~N}$ & 0.33 & 61 \\
\hline S6 & 0.48 & 0.54 & 0.27 & 0.31 & 0.31 & $\mathrm{~N}$ & 0.42 & 0.18 & 0.22 & 0.44 & 83 \\
\hline S7 & 0.34 & 0.30 & 0.50 & $\mathrm{~N}$ & $\mathrm{~N}$ & $\mathrm{~N}$ & 0.44 & $\mathrm{~N}$ & $\mathrm{~N}$ & 0.41 & 78 \\
\hline S8 & 0.49 & 0.50 & 0.42 & $\mathrm{~N}$ & $N$ & $\mathrm{~N}$ & 0.46 & 0.18 & $N$ & 0.46 & 80 \\
\hline S9 & 0.43 & 0.47 & 0.28 & $\mathrm{~N}$ & 0.23 & $\mathrm{~N}$ & 0.55 & 0.00 & 0.89 & 0.49 & 90 \\
\hline S10 & 0.59 & 0.72 & 0.38 & 0.56 & $\mathrm{~N}$ & $\mathrm{~N}$ & 0.59 & 0.30 & 0.53 & 0.57 & 89 \\
\hline S11 & 0.54 & 0.55 & 0.49 & $\mathrm{~N}$ & 0.62 & $\mathrm{~N}$ & 0.53 & 0.11 & 0.61 & 0.52 & 82 \\
\hline $\mathrm{S} 12$ & 0.60 & 0.70 & 0.42 & $N$ & 0.54 & $\mathrm{~N}$ & 0.52 & 0.45 & 0.47 & 0.55 & 82 \\
\hline $\mathrm{S} 13$ & 0.46 & 0.51 & 0.44 & 0.23 & 0.23 & $\mathrm{~N}$ & 0.46 & 0.36 & 0.78 & 0.47 & 80 \\
\hline S14 & 0.48 & 0.55 & 0.34 & $\mathrm{~N}$ & 0.54 & 0.35 & 0.57 & 0.23 & 0.39 & 0.49 & 87 \\
\hline S15 & 0.63 & 0.73 & 0.55 & 0.44 & $\mathrm{~N}$ & $\mathrm{~N}$ & 0.68 & 0.33 & 0.44 & 0.61 & 91 \\
\hline S16 & 0.37 & 0.44 & 0.26 & 0.31 & 0.23 & $\mathrm{~N}$ & 0.52 & 0.45 & $N$ & 0.45 & 79 \\
\hline Total & 0.49 & 0.53 & 0.39 & 0.41 & 0.40 & 0.28 & 0.49 & 0.25 & 0.52 & 0.48 & 81 \\
\hline MARI value > $0.2(\%)$ & 92 & 94 & 88 & 73 & 100 & 67 & 72 & 54 & 97 & 81 & \\
\hline
\end{tabular}

$\mathrm{N}$ : Not detected * All Enterobacteriaceae isolates tested 
MAR indices of isolates from different locations, it was only the Enterobacteriaceae (especially E. coli) and FS isolates that showed significant differences (ANOVA, $p<0.05$ ) between the MARI values at some locations. This is especially true for $\mathrm{S10}, \mathrm{S} 12$ and S15 versus S4, S5 and S7.

Correlation analysis between the percentage of resistance and the density of fecal indicators at the same location showed a strong, positive and significance $(p<0.001)$ correlation with correlation coefficients ( $r$ ) of 0.79 and 0.78 for FC and FS respectively. Furthermore, seawater samples from locations such as Alshatee refugee camp (S15), Nitsareem cross (S12), Wadi Gaza (S10) and the basin of Gaza fishing port (S14) showed the highest density of fecal indicators. At the same time, isolates from these locations exhibited the highest resistance. On the other hand, isolates from samples collected at locations such as S4 (Remas restaurant), S5 (Al zaeem restaurant) and S7 (Sonista restaurant) from Kan-Younis and Middle governorates showed lower levels of resistance and as expected, these locations showed lowest density of fecal indicators.

\section{Discussion}

Microbiological examination of marine samples for pathogenic bacteria is of great importance, representing a direct measurement of deleterious effect of microbiological pollution. Present investigation demonstrated higher densities of FS than that of FC in all locations. Such variation was consistent with the findings of Dufour A. (1977) [21] and may be attributed to the different rates of growth and survival of these microorganisms in marine environment [22] and to the differences in susceptibility to physical factor, such as exposures to varying level of sunlight intensities [23]. The findings that FC and FS populations in seawater are increased toward the north (Figure 2) could be attributed to the natural coastal processes dominating the Pal- estinian coastline such as waves regimes and wave generated long shore current which are responsible for generating net longshore transport to the north, thus, carrying more pollutants toward the northern locations.

The results of this study provide clear evidence of the considerable spread of multiple antimicrobial resistance among four groups of clinically important bacteria namely; Enterobacteriaceae, FS, $P$. aeruginosa and $S$. aureus isolates in the seawater samples from the different locations at Gaza strip. The occurrence of bacteria in aquatic environment with high resistance to antimicrobial may be an indication of the widespread and prolonged misuse of these antibacterial drugs in the Gaza strip [8].

The high value of resistance found among Enterobacteriaceae genera to ampicillin (98.7\%), amoxicillin $(97.1 \%)$ and cefuroxime (71.9\%) which all belong to $\beta$-Lactam was in agreement with that reported byAbo-State et al (2012) [24] and DebMandal et al (2011) [25].

Fecal isolates possessed maximum resistance to ampicillin (76.7\%) and penicillin G (75.1\%). Entertococci resistance to ampicillin is of great importance, since ampicillin is used in treatment of such infections [26]. Various rates of ampicillin resistance in both clinical and environmental isolates of FS isolates were previously reported from the Gaza strip $[4,10]$.

In the present study, $P$. aeruginosa isolates from marine environment demonstrated high resistance rate (> 50\%), with remarkable high resistance to imipenem (96.6\%), ertapenem (93.1\%), meropenem (86.2\%) and piperacillin (51.7). This high rate of resistance could be attributed to extended spectrum B-lactamase (ESBL) and metallo B-lactamase (MBL) encoding genes [27].

S. aureus showed high level of methicillin resistance as indicated by their resistance to oxacillin (61\%). Previously, Abu Hujier and Sharif (2008) had reported prevalence of Methicillin-resistant S. aureus (MRSA) of $22 \%$ from clinical isolates obtained 
from patients in Gaza strip [28]. More recently however, Al Laham (2012) reported MRSA prevalence of $62.1 \%$ in operation theaters at main hospitals of Gaza strip[5]. Previous studies from marine environments from other localities around the world found much lower percentages than the current study [29, 30]. The observed higher rate of resistance among S. aureus isolates in this study however, may be due to the inter-generic transfer of resistance among different genera of Gram-positive cocci and between Bacillus species and Staphylococci and Streptococci which may increase in aquatic environment[31].

The results of this study indicated that isolates belonging to Gram-negative bacteria (Enterobacteriaceae and $P$. aeruginosa) exhibited higher resistance than Gram-positive bacteria (FS and S. aureus), although the difference is not statistically significant $(P=0.085$, independent samples $t$ test). The predominance of antimicrobial resistance among Gram-negative bacteria has been reported previously [32].

This study revealed the occurrence of multidrug resistant (MDR) bacteria in coastal water of the Gaza strip. The varying frequencies of antimicrobial resistance found in the present study was generally consistent with those of other studies toward bacteria from different natural environments including seawater [33-35].

In the current study, $81 \%$ of the total isolates, $91.8 \%$ of Enterobacteriaceae, $72.1 \%$ of $\mathrm{FS}, 96.6 \%$ of $P$. eruginosa and $53.7 \%$ of $S$. aureus showed MAR index of more than 0.2 and up to 1 indicating very high degree of resistance. Calculation of MARI values of the sites revealed that all (the 16 locations) had a high overall MAR index value (> 0.2) and consequently, represent a high risk source of fecal pollution.

A comparison between fecal indicators and the percentage of resistance at the same location in this study showed a clear trend; i.e., as the density of fecal indicators increases, so did the percentage of resistant isolates. The findings of strong correlation between the densities of fecal indicators and the percentage of resistant isolates agrees with previous studies conducted in different localities around the world which showed positive correlations between the degree of pollution and bacterial resistance to antibiotics[12, 35].

The widespread of antibiotic resistant bacteria and fecal indicators in the shore of Alshatee refugee camp (S15) might due to the release of untreated wastewater into this region. In addition, (S12) location is exposed to continuous discharge from a nearby fish farm (possible source of antimicrobials and antimicrobial resistant pathogens).

The obtained results confirmed the presence of the multidrug resistance bacteria in the coastal water of Gaza strip. The prime source of antimicrobials in this area may be the hospitals; aquaculture and agriculture were antimicrobial are widely used as therapy for bacterial infections in humans and in animals as growth promoters . In addition, the effluents of Wadi Gaza, which mainly consist of untreated sewage, are discharged directly into the shore. Several studies reported that antibiotic resistance genes could be transferred in aquatic environments among pathogenic and nonpathogenic bacteria, making it a reservoir for resistance genes and thus, representing a high environmental risk for population[2, 36].

\section{Conclusions}

The findings in this study demonstrated the occurrence of high rates of multiple antibiotic resistance among potential pathogens isolated from seawater samples along the Gaza strip seashore. Vancomycin-resistant enterococci, MRSA, carbapenems-resistant $P$. eruginosa and MDR Enterobacteriaceae were recovered. This condition requires immediate actions of the concerned authorities to prevent untreated domestic and hospital wastewater from being discharged into seawater. 


\section{Acknowledgment}

The authors would like to express their appreciation for the financial support provided by the Research council of the Palestinian Ministry of Education and Al-Maqdisi Programme.

\section{References}

1. Refsdal A. To treat or not to treat: a proper use of hormones and antibiotics. Animal Reproduction Science 2000;60:109-19.

2. Baquero F, Martinez JL, Canton R. Antibiotics and antibiotic resistance in water environments. Current opinion in biotechnology 2008;19(3):260-65.

3. Sengupta S, Chattopadhyay M. Antibiotic resistance of bacteria: A global challenge. Resonance 2012;17(2):177-79.

4. Al-Jarousha A-MK, Saed A, Afifi H. Prevalence of Multidrug Resistant Enterococci in Nosocomial Infection in Gaza Strip. Journal of Al-Aqsa University (natural sciences series) 2008;12:15- 24.

5. Al Laham N. Distribution and Antimicrobial Resistance Pattern of Bacteria Isolated from Operation Theaters at Gaza Strip. Journal of Al Azhar University-Gaza (Natural Sciences) 2012;14:19-34.

6. El Astal Z. Increasing Ciprofloxacin Resistance Among Prevalent Urinary Tract Bacterial Isolates in Gaza Strip, Palestine. Journal of Biomedicine and Biotechnology 2005;3:238-41.

7. Elmanama A. Vancomycin Resistant Enterococci (VRE) among Non -Hospitalized Individuals in Gaza City, Palestine. Journal of Al Azhar University-Gaza (Natural Sciences) 2008;10:31- 40.

8. Elmanama A, Abdelateef N. Antimicrobial Resistance of Enteric Pathogens Isolated from Acute Gastroenteritis Patients in Gaza strip, Palestine. The International Arabic Journal of Antimicrobial Agents 2012;2(4).

9. Elmanama A, Elaiwa N, El-Ottol A, Abu-Elamreen F. Antibiotic resistance of uropathogens isolated from Al-Shifa hospital in Gaza Strip in 2002. Journal of Chemotherapy 2006;18(3):298302.

10. Elmanama A, ElKichaoui A, Mohsin M. Contribution of hospital wastewater to the spread of antibiotic resistance in comparison to non-health institution. Journal of Al-Aqsa University (natural sciences series) 2006;10:108-21.

11. Hatha A, Gomathinayagam P, Lakshmanaperumalsamy $P$. Incidence of multiple antibiotic resistant Escherichia coli in the Bhavani River. World Journal of Microbiology and Biotechnology 1993;9(5):609-10.

12. Oliveira A, Franca $P$, Pinto A. Antimicrobial resistance of heterotrophic marine bacteria isolated from seawater and sands of recreational beaches with different organic pollution levels in southeastern Brazil: evidences of resistance dissemination. Environmental monitoring and assessment 2010;169:375-84.

13. Oliveira A, Pinhata J. Antimicrobial resistance and species composition of Enteroccocus spp. isolated from waters and sands of marine recreational beaches in southern Brazil. Water research 2008;42:2242- 50.

14. Mudryk Z, Perliński P., Skórczewski P. Detection of antibiotic resistant bacteria inhabiting the sand of nonrecreational marine beach. Marine Pollution Bulletin 2010;60(2):207- 14.

15. Al-Bahry S, Mahmoud I, Al-Belushi K, Elshafie A, Al-Harthy A, Bakheit C. Coastal sewage discharge and its impact on fish with reference to antibiotic resistant enteric bacteria and enteric pathogens as bio-indicators of pollution. Chemosphere 2009;77(11):1534-39.

16. El-Zanfaly $\mathrm{H}$. The need for new microbiological water quality criteria. Water Science and Technology 1991;24(2):43- 48.

17. WHO. World Health Organization, Manual for recreational water and Beach quality monitoring and Assessment. European center for environment and health; 1995.

18. CLSI. Clinical and Laboratory Standards Institute, Performance Standards for Antimicrobial Susceptibility Testing; Twenty-First Informational Supplement. M02-A10 and M07-A8. Wayne, PA., USA; 2011

19. Krumperman P. Multiple antibiotic resistance indexing Escherichia coli to identify risk sources of faecal contamination of foods. Applied and Environmental Microbiology 1983;46(1):165- 70.

20. Kaspar C, Burgess J, Knight I, Colwell R. Antibiotic Resistance Indexing of Escherichia coli to Identify Sources of Fecal Contamination in Water. Canadian journal of microbiology 1990;36:891- 94

21. Dufour A. Escherichia coli: The faecal coliforms. In Bacterial Indicators/Healt Hazards Associated with Water. American Society for Testing and Materials 1977;635:48-58.

22. Crane bS, Moore J. Modeling enteric bacterial die-off: a review. Water, air, and soil Pollution 1986:27(3-4):411-39.

23. Sieracki M. The Effects of Short Exposures of Natural Sunlight on the Decay Rates of Enteric Bacteria and A coliphage in a Simulated Sewage Outfall Microcosm [Providence, RI.: University of Rhode Island; 1980.

24. Abo-State M, Mahdy H, Ezzat S, Abd El Shakour E, El-Bahnasawy M. Antimicrobial resistance profiles of enterobacteriaceae isolated from Rosetta branch of River Nile, Egypt. World Applied Sciences Journal 2012;19(9):1234-43.

25. DebMandal M, Mandal S, Pal NK. Antibiotic resistance prevalence and pattern in environmental bacterial isolates. The Open Antimicrobial Agents Journal 2011;3:45-52.

26. Barisic Z, Punda-Polić V. Antibiotic resistance among enterococcal strains isolated from clinical specimens. International Journal of Antimicrobial Agents 2000;16(1):6568.

27. Picao R, Poirel L, Gales A, Nordmann P. Diversity of $\beta$-lactamases produced by ceftazidime-resistant Pseudomonas aeruginosa isolates causing bloodstream infections in Brazil. Antimicrobial agents and chemotherapy 2009;53(9):3908-13.

28. Abu Hujier N, Sharif F. Detection of methicillin-resistant Staphylococcus aureus in nosocomial infections in Gaza Strip. African Journal of Microbiology Research 2008;2(9):235-41.

29. Yamahara K, Sassoubre L, Goodwin K, Boehm A. Occurrence and persistence of human pathogens and indicator organisms 
in beach sands along the California coast. Applied and Environmental Microbiology 2012;78(6):1733-45.

30. Goodwin K, McNay M, Cao Y, Ebentier D, Madison M, Griffith J. A multi-beach study of Staphylococcus aureus, MRSA, and enterococci in seawater and beach sand. Water research 2012;46(13):4195- 207.

31. Schaberg DR, Zervos MJ. Intergeneric and interspecies gene exchange in gram-positive cocci. Antimicrobial agents and chemotherapy 1986;30(6):817.

32. Ab Rahman N, Chowdhury AJK, Abidin ZAZ. Antibiotic resistant bacteria from sediment of coastal water of Pahang, Malaysia. Jurnal Teknologi 2015;77(24):65-70.

33. Neela F, Nonaka L, Suzuki S. The diversity of multi-drug resistance profiles in tetracycline-resistant Vibrio species isolated from coastal sediments and seawater. Journal of Microbiology (Seoul) 2007;45:64- 68.

34. Maloo A, Borade S, Dhawde R, Gajbhiye S, Dastager S. Occurrence and distribution of multiple antibiotic-resistant bacteria of Enterobacteriaceae family in waters of Veraval coast, India. Environmental and Experimental Biology 2014;12:43- 50.

35. Kimiran-Edrem A, Arslan E, Yurudu N, Zeybek Z, Dogruoz $N$, Cotuk A. Isolation and identification of enterococci from seawater samples: assessment of their resistance to antibiotics and heavy metals. Environmental Monitoring and Assessment 2007;125:219- 28

36. Finley RL, Collignon P, Larsson DGJ, McEwen SA, Li X-Z, Gaze WH, "et al.". The scourge of antibiotic resistance: the important role of the environment. Clinical Infectious Diseases 2013;57:704-10

\section{Comment on this article:}

\section{f) $B$ in $\mathbf{S}$}

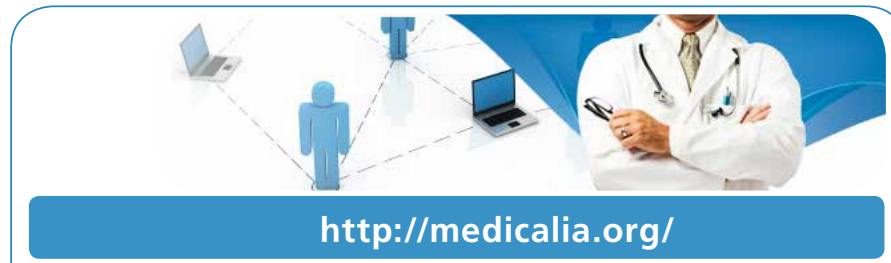

Where Doctors exchange clinical experiences, review their cases and share clinical knowledge. You can also access lots of medical publications for free. Join Now!

\section{Publish with iMedPub}

http://www.imed.pub

The Journal is an open access peer-reviewed journal that publishes scientific papers about all aspects of antimicrobials. The journal will publish original research articles, reviews, brief reports and case reports dealing with basic and clinical antibacterial agents, antiviral, antiprotozoals, antituberculuous, antifungal and antihelminthes agents.

All manuscripts must be prepared in English, and are subject to a rigorous and fair peer-review process. Accepted papers will immediately appear online.

The journal aims to advance the knowledge, attitude and the research of chemotherapy in the Arabic world in cooperation with international, national scientific and public societies as well as research centers with similar aims and objectives. 